\title{
Design and Digital Implementation of Controller for PMSM Using Extended Kalman Filter
}

\author{
Mamatha Gowda, Warsame H. Ali, Penrose Cofie, John Fuller \\ Department of Electrical and Computer Engineering, Prairie View A\&M University, Prairie View, USA \\ Email:mgowda@student.pvamu.edu,whali@pvamu.edu,pscofie@pvamu.edu,jhfuller@pvamu.edu
}

Received October 19, 2013; revised November 19, 2013; accepted November 26, 2013

Copyright (C) 2013 Mamatha Gowda et al. This is an open access article distributed under the Creative Commons Attribution License, which permits unrestricted use, distribution, and reproduction in any medium, provided the original work is properly cited. In accordance of the Creative Commons Attribution License all Copyrights (C) 2013 are reserved for SCIRP and the owner of the intellectual property Mamatha Gowda et al. All Copyright (C) 2013 are guarded by law and by SCIRP as a guardian.

\begin{abstract}
A novel digital implementation of speed controller for a Permanent Magnet Synchronous Motor (PMSM) with disturbance rejection using conventional observer combined with Extended Kalman Filter (EKF) is proposed. First, the EKF is constructed to achieve a precise estimation of the speed and current from the noisy measurement. Second, a proportional integral derivative (PID) controller is developed based on Linear Quadratic Regulator (LQR) to achieve speed command tracking performance. Then, an observer is designed and its error is utilized to provide load disturbance compensation. The proposed method greatly enhances the PMSM performance by reducing the control signal variation as well as the disturbance. The speed control performance is significantly improved compared to the case when we have an observer acting alone. The simulation results for the speed response and variation of the states when the PMSM is subjected to the load disturbance are presented. The results verify the effectiveness of the proposed method.
\end{abstract}

Keywords: Permanent Magnet Synchronous Motor; Extended Kalman Filter; PID; Vector Control; Observer

\section{Introduction}

Permanent Magnet synchronous Motor (PMSM) has a high torque/inertia ratio, high speed, high efficiency as well as high reliability and is of compact size. These qualities render PMSM as one of the most applicable AC machines for servo control applications and PMSM is therefore gaining extensive research attention in recent years [1-3]. PMSM weighs less and is of low maintenance; it offers many advantages in the high performance application areas such as in robotics, aerospace, navigation and many more. The modeling and control of the PMSM is complex because of two main reasons: 1) the multi-input nature of the motor, 2) the coupling between the stator current and rotor speed are non-linear. For high performance of PMSM that drives the vector control theory is applied, in which 3-ф stationary frame transforms into 2- $\phi$ synchronously rotating rotor reference frame; thus the flux and torque can be controlled independently, similar to the DC motor [4-6]. Though, the vector control is a complex control technique, the progress in the development of fast semiconductors switches and cost efficiency micro-controller has made the vector control fea- sible. PMSM uses known rotor shaft position as well as the inverter to control the armature currents, and is usually employed in direct drive system. The direct drive systems are more prone to load variations and these variations directly impact the motor shaft; this deteriorates the performance of the system. In order to mitigate these defects, the disturbance rejection control technique is used.

In this paper a vector control method is developed and implemented by means of a conventional observer combined with Extended Kalman Filter algorithm to provide the speed control and disturbance rejection. In the vector control method, to achieve better control performance, it is important to know the information of the rotor speed and position. Here, state space representation of the model and observer is obtained. Utilizing the state space model, a PID controller is designed using Linear Quadratic Regulator (LQR) approach [7]. Commonly, the aim of the observer design is to reduce the observation error, but it is used to serve as feed forward compensation for the load disturbance in the proposed method [8].

Many research works have been done in speed and position estimation of PMSM using sliding mode, high 
frequency signal injection method, adaptive control theory, fuzzy control, state observer, EKF [9-16]. In all, EKF is more attractive as well as popular and is continuously being used in research and applications because it delivers rapid, precise, and accurate estimation. In many applications EKF is implemented because of its low-pass filter characteristics $[17,18]$. The feedback gain used in EKF achieves quick convergence and provides stability for the observer.

In this article, the conventional observer combined with the Extended Kalman Filter is presented. The accurate estimation of states is very essential to achieve better control and performance of the PMSM drives. Here the EKF is utilized for the precise estimation of the rotor speed and stator q-axis current. Since the drive speed and drive current are measured directly from the machine terminals contain noise, they are not precise for speed control. In the proposed approach, the speed and q-axis current are estimated accurately by introducing EKF algorithm theory. The estimated current acts as an input to the state observer while the estimated speed is compared with the reference speed. The proposed method yields a smooth and quick speed tracking, reduction in the disturbance applied to the system, and better control of the control signal variation. The overall system performance is greatly enhanced with the proposed method.

\section{Model of PMSM}

The stator voltage and stator flux linkages equations in the rotor references frame are [4]:

$$
\begin{gathered}
v_{s d}=R_{s} i_{s d}+L_{s} \frac{\mathrm{d}}{\mathrm{d} t} i_{s d}-\omega_{m} L_{s} i_{s q}, \\
v_{s q}=R_{s} i_{s q}+L_{s} \frac{\mathrm{d}}{\mathrm{d} t} i_{s q}+\omega_{m}\left(L_{s} i_{s d}+\lambda_{f d}\right), \\
\lambda_{s d}=L_{s} i_{s d}+\lambda_{f d}, \\
\lambda_{s q}=L_{s} i_{s q}
\end{gathered}
$$

where $v_{s d}, v_{s q}, i_{s d}, i_{s q}, \lambda_{s d}, \lambda_{s q}$ are d-axis and qaxis voltages, currents and flux linkages respectively. $R_{s}, L_{s}$ are the stator winding resistance and inductance.
The electromagnetic torque generated and the acceleration is given by:

$$
\begin{gathered}
T_{e m}=\frac{p}{2} \lambda_{f d} \cdot i_{s q}, \\
\frac{\mathrm{d}}{\mathrm{d} t} \omega_{\text {mech }}=\frac{T_{e m}-T_{L}}{J}-\frac{B}{J} \omega_{\text {mech }}, \\
\omega_{m}=\frac{p}{2} \omega_{\text {mech }}
\end{gathered}
$$

where $\omega_{\text {mech }}$ is the speed of the motor and $p$ is the number of poles.

Since the torque developed by the motor is directly proportional to the motor drive current, it is difficult to control the drive current directly. Therefore the drive current is indirectly controlled through the input voltage. The simplified model of the PMSM q-axis subsystem is shown in Figure 1.

In vector control, assuming $i_{d s}=0$, the state-space model of the PMSM q-axis subsystem is derived as [8]:

$\left[\begin{array}{c}i_{s q} \\ \dot{\omega}_{\text {mech }}\end{array}\right]=\left[\begin{array}{cc}-\frac{R_{s}}{L_{s}} & -\left(\frac{\lambda_{f d}}{L_{s}} \cdot \frac{p}{2}\right) \\ \left(\frac{p}{2} \cdot \frac{\lambda_{f d}}{J}\right) & -\frac{B}{J}\end{array}\right]\left[\begin{array}{c}i_{s q} \\ \omega_{\text {mech }}\end{array}\right]+\left[\begin{array}{c}\frac{1}{L_{s}} \\ 0\end{array}\right]\left[v_{s q}\right]$

For the speed controller design, the system output is

$$
[y]=\left[\begin{array}{ll}
0 & 1
\end{array}\right]\left[\begin{array}{c}
i_{s q} \\
\omega_{\text {mech }}
\end{array}\right]
$$

If the motor output is considered as the drive current, then the motor output is given by:

$$
\left[y^{\prime}\right]=\left[\begin{array}{ll}
1 & 0
\end{array}\right]\left[\begin{array}{c}
i_{s q} \\
\omega_{\text {mech }}
\end{array}\right]
$$

\section{PID Parameters Tuning with State-Feedback and State-Feed forward LQR}

The controller is designed as a single-input—single-output (SISO) system. The following discussion is based on the

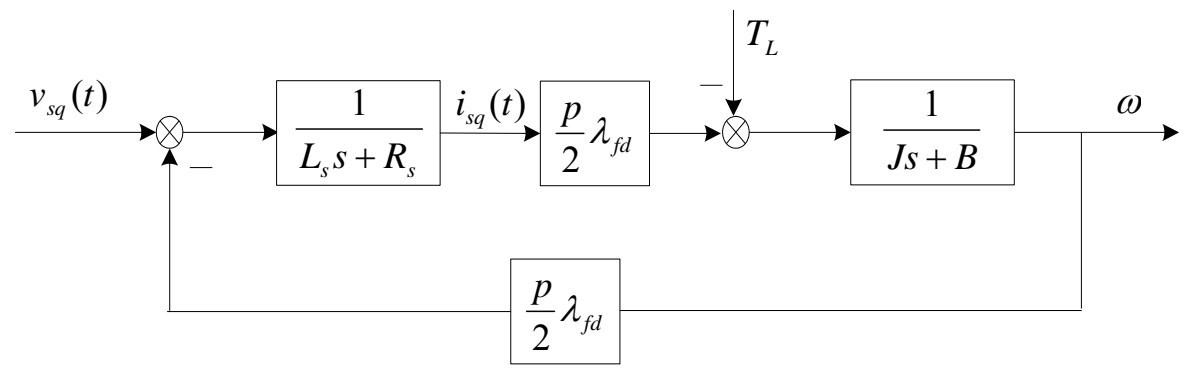

Figure 1. Q-axis subsystem of a simplified PMSM. 
$q$-axis controller/observer design [8].

The state space model of the simplified PMSM, $G 1(s)$, with reference to the q-axis is:

$$
\begin{gathered}
\dot{x}_{1}(t)=A_{1} x_{1}(t)+B_{1} u_{1}(t), x_{1}(0)=x_{10} \\
y_{1}(t)=C_{1} x_{1}(t)
\end{gathered}
$$

where, $x_{1}(t) \in R^{2 \times 1}, \quad u_{1}(t) \in R^{1 \times 1}, \quad y_{2}(t) \in R^{1 \times 1}$, and $\mathrm{A}_{1}$, $\mathrm{B}_{1}$ and $\mathrm{C}_{1}$ are constant matrices.

The entire system output is the sum of the motor output and load disturbance and is given by:

$$
y(t)=y_{1}(t)+d(t)
$$

where $y(t) \in R^{1 \times 1}, d(t) \in R^{1 \times 1}$

The state space model of the speed controller, $G_{2}(s)$, can be written as:

$$
\begin{gathered}
\dot{x}_{2}(t)=A_{2} x_{2}(t)+B_{2} u_{2}(t), \quad x_{2}(0)=x_{20}, \\
y_{2}(t)=C_{2} x_{2}(t)=u_{1}(t), \\
u_{2}(t)=-y(t)+E_{c} r(t)
\end{gathered}
$$

where $\quad x_{2}(t) \in R^{2 \times 1}, \quad u_{2}(t) \in R^{1 \times 1} \quad, \quad y_{2}(t) \in R^{1 \times 1}$, $r(t) \in R^{1 \times 1}$, and $A_{2}, B_{2}, C_{2}, E_{c}$ are constant matrices.

In order to convert the PID tuning problem to an optimal design, we modify the closed loop cascade system into an augmented system with $d(t)=0$. The result is the following equation:

$$
\begin{gathered}
\dot{x}_{e}(t)=A_{e} x_{e}(t)+B_{e} u_{1}(t)+E_{e} r(t) \\
y_{e}(t)=y_{1}(t)=C_{e} x_{e}(t)
\end{gathered}
$$

where

$$
\begin{aligned}
& A_{e}=\left[\begin{array}{cc}
A_{1} & 0 \\
-B_{2} C_{1} & A_{2}
\end{array}\right], B_{e}=\left[\begin{array}{c}
B_{1} \\
0
\end{array}\right], E_{e}=\left[\begin{array}{c}
0 \\
B_{2} E_{c}
\end{array}\right], \\
& x_{e}=\left[\begin{array}{l}
x_{1}(t) \\
x_{2}(t)
\end{array}\right], C_{e}=\left[\begin{array}{ll}
C_{1} & 0
\end{array}\right]
\end{aligned}
$$

The resulting state-feedback LQR for the augmented system is:

$$
u_{1}(t)=-K_{e} x_{e}(t)=-K_{1} x_{1}(t)-K_{2} x_{2}(t)
$$

where $K_{1} \in R^{1 \times 2}, K_{2} \in R^{1 \times 2}$.

The quadratic cost function for the system $J$, is given as:

$$
J=\int_{0}^{\infty}\left[x_{e}^{\mathrm{T}}(t) Q x_{e}(t)+u_{1}^{\mathrm{T}}(t) R u_{1}(t)\right] \mathrm{d} t
$$

where $Q \geq 0, R>0$, which represent the states variation and control energy consumption, respectively.

The optimal state-feedback control gain which minimizes the performance index is given by:

$$
K_{e}=R^{-1} B_{e}^{\mathrm{T}} P .
$$

The solution of the revised Riccati equation is given by:

$$
P\left(A_{e}+h I\right)+\left(A_{e}+h I\right)^{\mathrm{T}} P-P B_{e} R^{-1} B_{e}^{\mathrm{T}} P+Q=0
$$

where $P>0, h>0$.

The motor states feedback actually act as the proportional and derivative controller $\left\{K_{1} x_{1}(t)\right\}$ respectively and the controller act as an integral only. Then $K_{2}$ is a gain for the integral controller. Hence, the total control law is equivalent to a PID controller. By choosing the desired values of $\mathrm{h}$ and the weighting matrices $Q$ and $R$, the control gain can be determined. The block diagram of the designed augmented system including the controller is shown in the Figure 2.

The calculated control gains are given by:

$$
\begin{gathered}
K_{1}=\left[\begin{array}{ll}
0.2241 & 0.0030
\end{array}\right], \\
K_{2}=[-0.1333] .
\end{gathered}
$$

\section{Design of Observer}

A state observer is constructed mainly to achieve the speed control and disturbance rejection. The observation error and properly adjusted observer gain can provide feed-forward compensation for the output disturbance. is:

Suppose the state space model of the PMSM $G_{1}(s)$

$$
\begin{gathered}
\dot{x}_{1}(t)=A_{1} x_{1}(t)+B_{1} u_{1}(t), \\
y_{1}(t)=C_{1} x_{1}(t)
\end{gathered}
$$

with the entire system output being the sum of the motor output and load disturbance as :

$$
y(t)=y_{1}(t)+d(t) .
$$

The design of an observer, whose dynamic function is the same as that of the motor is as follows (see Equation (22)):

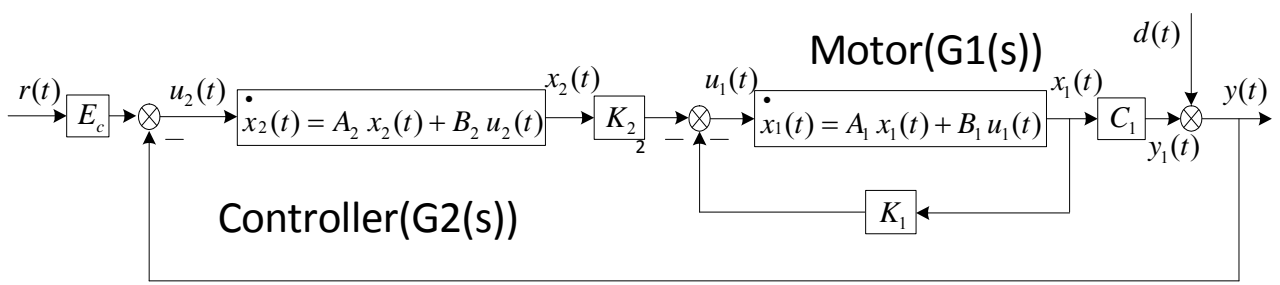

Figure 2. PID controller system. 


$$
\dot{\hat{x}}_{1}(t)=A_{1} \hat{x}_{1}(t)+B_{1} u_{1}(t)-J_{o}\left[C_{1} \hat{x}_{1}(t)-y(t)\right]
$$

where $\hat{x}_{1}(t)$ is an observed state and $x_{1}(t)$ is the real state.

Then

$$
\dot{\hat{x}}_{1}(t)=A_{1} \hat{x}_{1}(t)+B_{1} u_{1}(t)-J_{o}\left[C_{1} \hat{x}_{1}(t)-C_{1} x_{1}(t)-d(t)\right]
$$

The observation error is expressed as:

$$
e(t)=\hat{x}_{1}(t)-x_{1}(t) \text {. }
$$

The observation error dynamic function is then given by:

$$
\dot{e}(t)=\left(A_{1}-J_{o} C_{1}\right) e(t)+J_{o} d(t)
$$

Applying the Laplace transform, we get

$$
e(s)=\left[s I-\left(A_{1}-J_{o} C_{1}\right)\right]^{-1} J_{o} \cdot d(s) .
$$

From the above equation it is clear that the observation error will inevitably exist due to the load disturbance, and then the observed-state feedback can be regarded as:

$$
K_{1} \hat{x}_{1}(t)=K_{1} x_{1}(t)+K_{1} e(t)
$$

where, the term $K_{1} x_{1}(t)$ is the exact motor state feedback, while the term $K_{1} e(t)$ comes from the observation error. The PID controller system including the observer structure is shown in the Figure 3.

The feedback of the observation error actually acts as feed forward compensation for the load disturbance. Also the proper adjustment of the observer gain makes sure that the system is less affected by the load disturbance and provides additional feed forward compensation.

The speed signal differentiated through the position output of the encoder is very noisy. Thus $i_{s d}$ instead of $\omega_{\text {mech }}$ can be regarded as the system output in the following observer design. Selecting appropriate values for $h, Q$ and $R$, the revised Riccati equation is solved as follows [8]:

$$
P\left(A_{d}+h I\right)+\left(A_{d}+h I\right)^{\mathrm{T}} P-P B_{d} R^{-1} B_{d}^{\mathrm{T}} P+Q=0
$$

$$
J_{o}=\left(R^{-1} B_{d}^{\mathrm{T}} P\right)^{\mathrm{T}}=\left[\begin{array}{c}
118.1727 \\
-120.6678
\end{array}\right]
$$

where $A_{d}=A_{1}^{\mathrm{T}}, B_{d}=C_{1}^{\mathrm{T}}, C_{d}=B_{1}^{\mathrm{T}}$.

\section{State Observer Based Extended Kalman Filter}

The Extended Kalman Filter is a set of mathematical equations which produces the optimal estimation of the state system based on least square method. The EKF estimates the process by using a feedback control. The EKF provides considerable good tolerance for the mathematical model error and noises in the measurement inaccuracy [19].

The state space model of the simplified PMSM given by "(11a)" and "(11b)" is the non-linear system. To apply the EKF algorithm, the system needs be discretized and linearized [20].

The discrete approximated equation is given by:

$$
\begin{gathered}
x_{k}=(I+A T) x_{k-1}+B T u_{k}, \\
y_{k}=c x_{k} .
\end{gathered}
$$

The nonlinear stochastic equation is:

$$
f\left(x_{k-1}, u_{k}\right)=\left[\begin{array}{c}
\left(1-\frac{T R_{s}}{L_{s}}\right) i_{s q}-\left(\frac{T \lambda_{f d}}{L_{s}} \cdot \frac{p}{2}\right) \omega_{\text {mech }}+\frac{T}{L_{s}}\left[v_{s q}\right] \\
\left(\frac{T p}{2} \cdot \frac{\lambda_{f d}}{J}\right) i_{s q}+\left(1-\frac{B}{J}\right) \omega_{\text {mech }}
\end{array}\right]
$$

The Jacobian matrices of the partial derivative of $f$ and $\mathrm{h}$ with respect to $\mathrm{x}$ are:

$$
\begin{gathered}
A_{k}=\frac{\partial f\left(x_{k}, u_{k}\right)}{\partial x} \mid x_{k}=\hat{x}_{k}, \\
H_{k}=\frac{\partial h\left(x_{k}\right)}{\partial x} \mid x_{k}=\hat{x}_{k}
\end{gathered}
$$

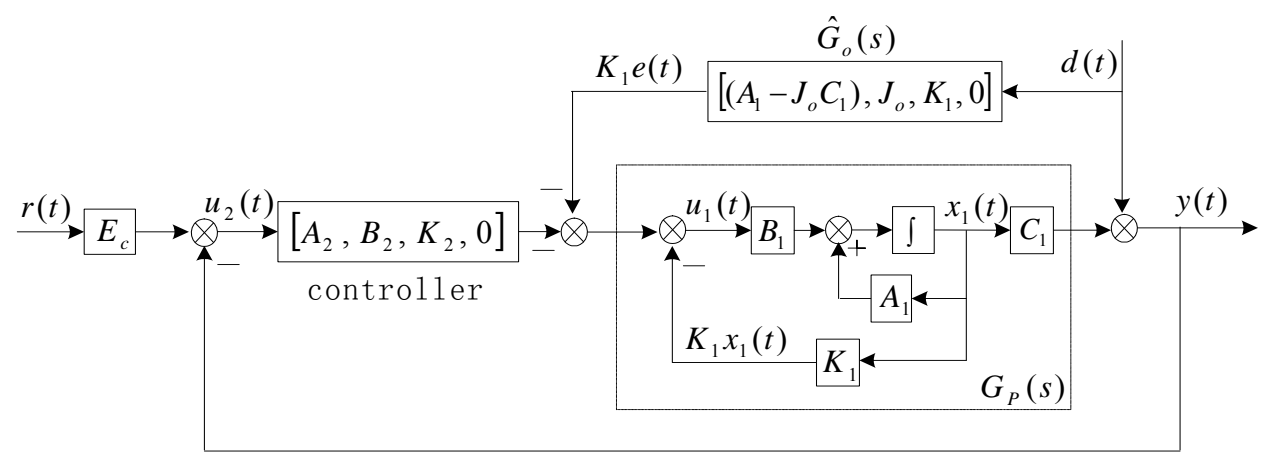

Figure 3. Observer structure. 
The motor nonlinear state equations given in the discretized form is as follows:

$$
\begin{gathered}
x_{k}=f\left(x_{k-1}, u_{k}\right)+w_{k}, \\
y_{k}=h\left(x_{k}\right)+v_{k}
\end{gathered}
$$

where $w_{k}$ and $v_{k}$ are zero-mean White Gaussian noise process and measurement noise with covariance $Q$ and $R$. Mainly, there are two states in the Extended Kalman Filter, namely the prediction state and the correction state.

In the prediction state also called the time update, the optimal state estimate $\hat{x}$ and state covariance $P$ are predicted.

$$
\left.\begin{array}{l}
\hat{x}_{p k}=f\left(\hat{x}_{k-1}, u, 0\right) \\
\hat{P}_{p k}=A_{k} \hat{p}_{k-1} A_{k}^{\mathrm{T}}+Q
\end{array}\right\} \text { Time update }
$$

In the correction state also called the measurement update, the predicted state estimate $\hat{x}$ and covariance matrix $\mathrm{P}$ are corrected as follows:

$$
\left.\begin{array}{l}
K_{k}=\hat{P}_{p k} H_{k}^{\mathrm{T}}\left(H_{k} \hat{P}_{p k} H_{k}^{\mathrm{T}}+R\right)^{-1} \\
\hat{x}_{c k}=\hat{x}_{p k}+K_{k}\left(y_{k}-H_{k}\left(\hat{x}_{p k}\right)\right) \\
\hat{P}_{c k}=\left(I-K_{k} H_{k}\right) \hat{P}_{p k}
\end{array}\right\} \text { Measurement update }
$$

The important and difficult part in the design of the EKF is choosing the proper values for the covariance matrices $Q$ and $R[21,22]$. The change of values of co- variance matrices affects both the dynamic and steadystate. By using trial and error method, a suitable set of values of $Q$ and $R$ are selected to insure better stability and convergence time.

The chosen values of $Q, R$ and $P$ are:

$$
Q=\left[\begin{array}{cc}
0.008 & 0 \\
0 & 1.5
\end{array}\right] \quad R=[0.02] \quad P=\left[\begin{array}{ll}
1 & 0 \\
0 & 1
\end{array}\right]
$$

\section{Simulation Results}

The PMSM model is constructed to verify the speed control and load disturbance rejection using the conventional observer combined with EKF. The simulation is implemented using MAT Lab/Simulink. The parameter of the motor model is given in Table 1. Based on optimal control theory, the desired control gain $\mathrm{K} 1$ and $\mathrm{K} 2$ and optimal observer gain (Jo) are determined and the filter gain is obtained using EKF algorithm. The output drive current and speed are estimated through the observer theory and EKF algorithm is implemented using S-Function block. The input to the S-Function block is taken directly from the machine terminals. The noise-free, accurately estimated output current is fed to the observer as input while the estimated speed is compared with reference speed. At the output, the motor response is checked and the disturbance rejection is observed. The block diagram used in the simulation is as shown in the below Figure 4 and the simulation results are shown in Figures 5-10.

With the reference speed of $200 \mathrm{rad} / \mathrm{s}$, the simulation

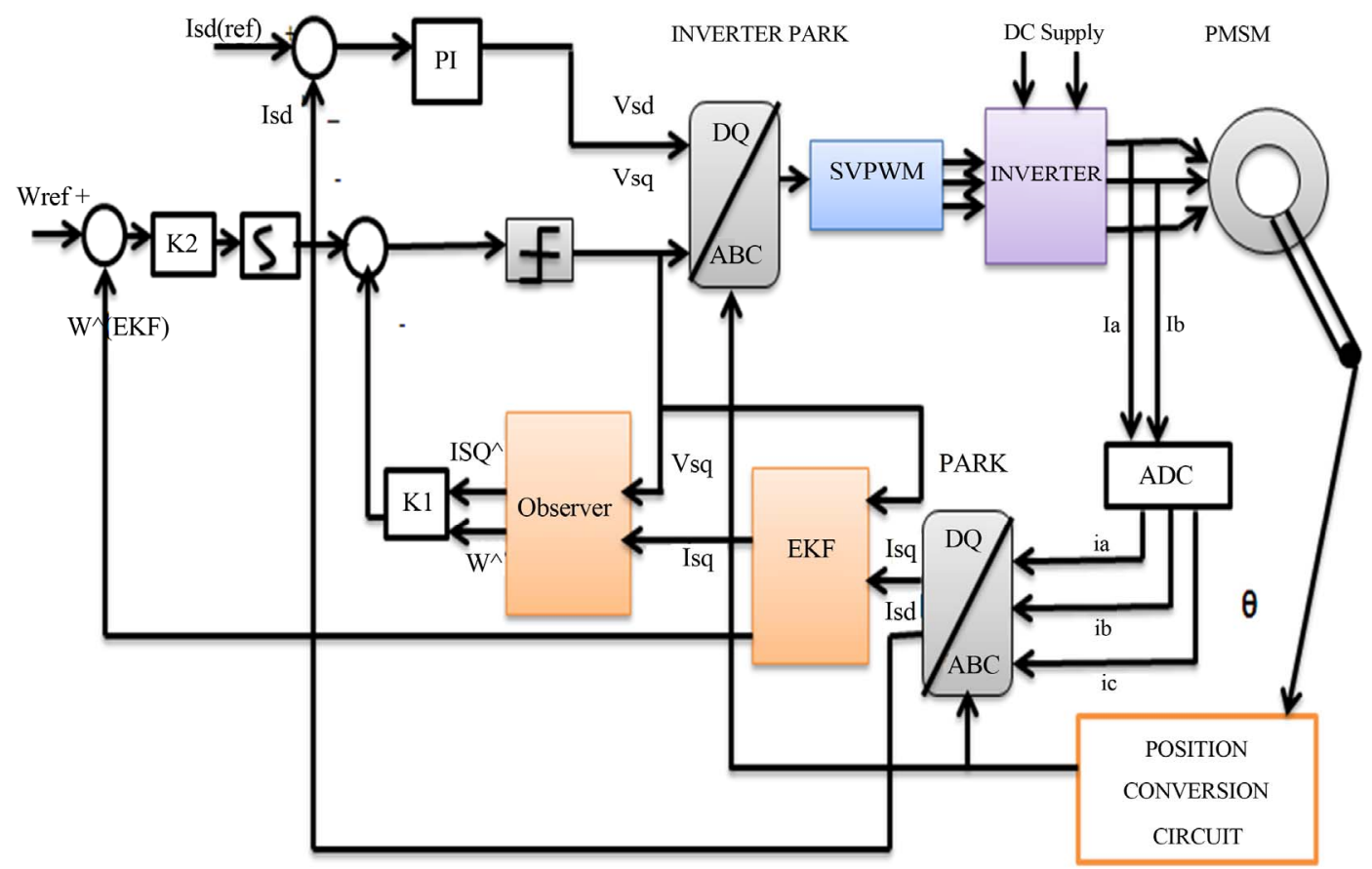

Figure 4. Block diagram of PMSM drive with observer combined with EKF. 
Table 1. PMSM parameter.

\begin{tabular}{cccc}
\hline Variable & Physical Meaning & Value & Unit \\
\hline$R_{s}$ & Armature Resistance & 0.1127 & $\Omega$ \\
$L_{s}$ & Armature Inductance & $3.63 \mathrm{e}-4$ & $\mathrm{H}$ \\
$J$ & Moment of Inertia & $1.2677 \mathrm{e}-4$ & $\mathrm{Kg} \cdot \mathrm{m}^{2}$ \\
$B$ & Damping Coefficient & $2.4857 \mathrm{e}-4$ & $\mathrm{~N} \cdot \mathrm{m} / \mathrm{rad} / \mathrm{s}$ \\
$\lambda_{f d}$ & Stator Flux Linkage & 0.0131 & $\mathrm{~V} / \mathrm{rad} / \mathrm{s}$ \\
$p$ & Poles number & 10 & \\
$T_{L 0}$ & Static Friction & 0.0237 & $\mathrm{~N} \cdot \mathrm{m}$ \\
\hline
\end{tabular}

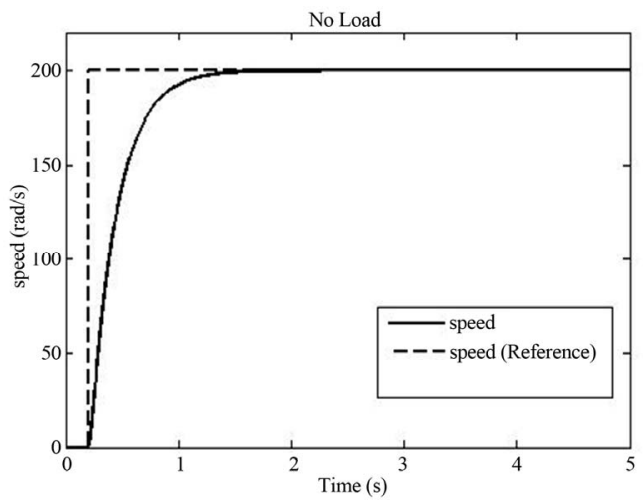

(a)
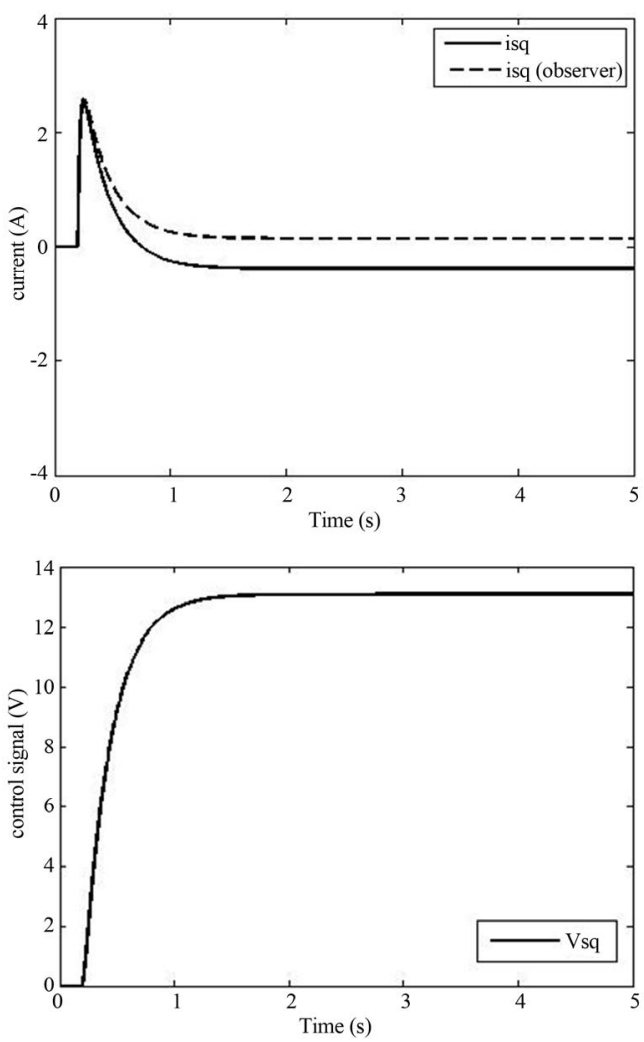

(b)

Figure 5. (a) Speed response; (b) control signal response for observer acting alone (no load).

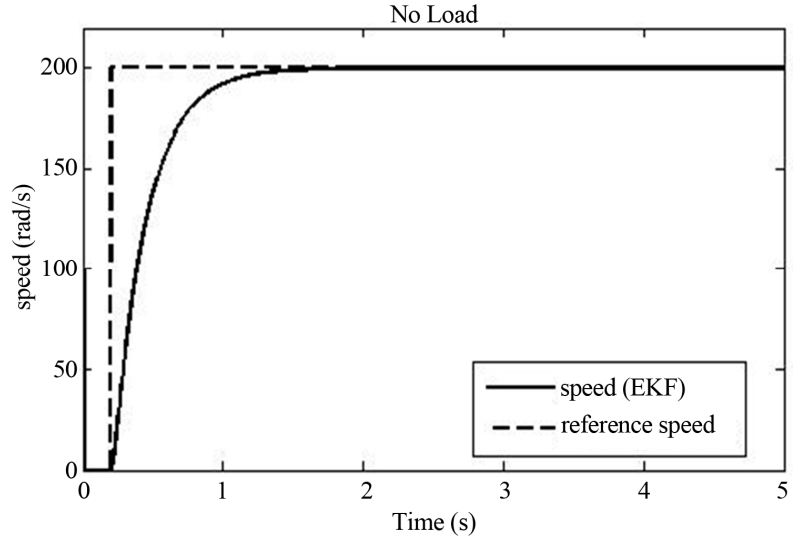

(a)
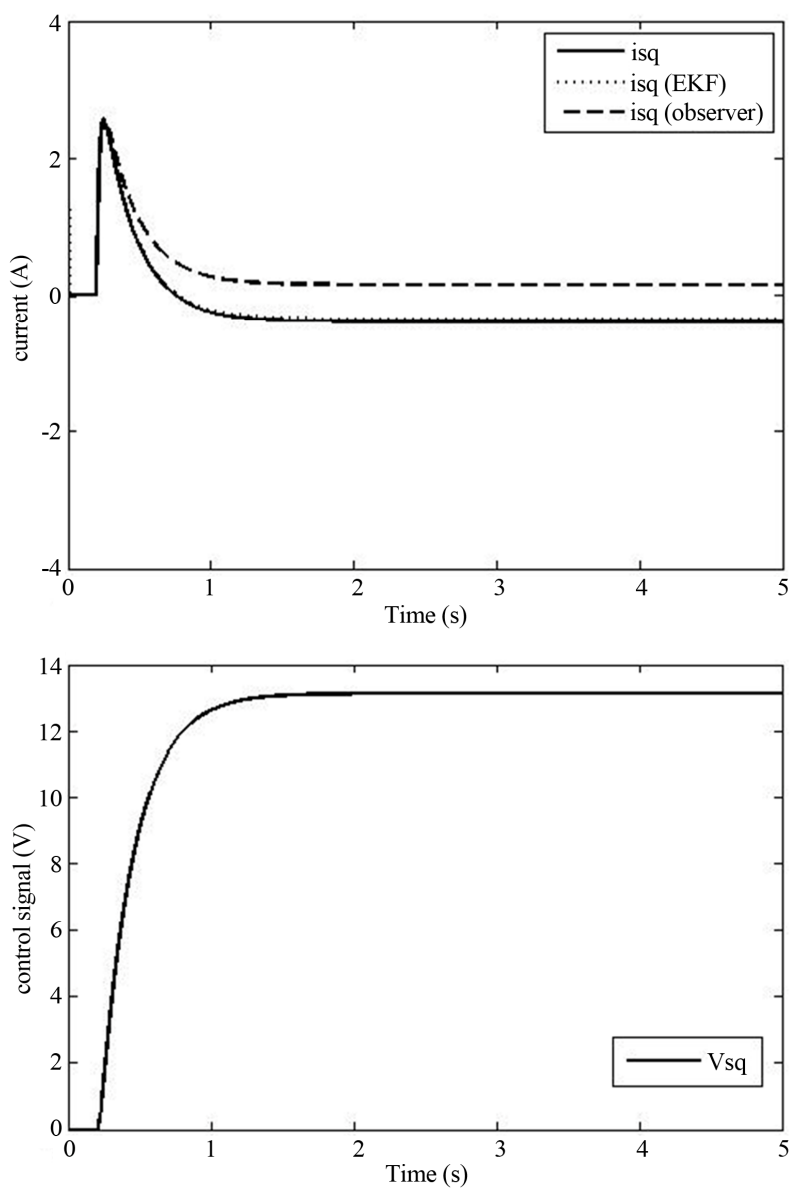

(b)

Figure 6. (a) Speed response; (b) control signal response for observer combined with EKF (no load).

results with observer acting alone and observer combined with EKF are shown in Figures 5 and 6, under no load condition. It is observed that the motor speed tracks the reference speed quickly and smoothly.

To account for the speed estimation performance of the observer acting alone and observer combined with EKF for a step change in steady state operation of PMSM, 


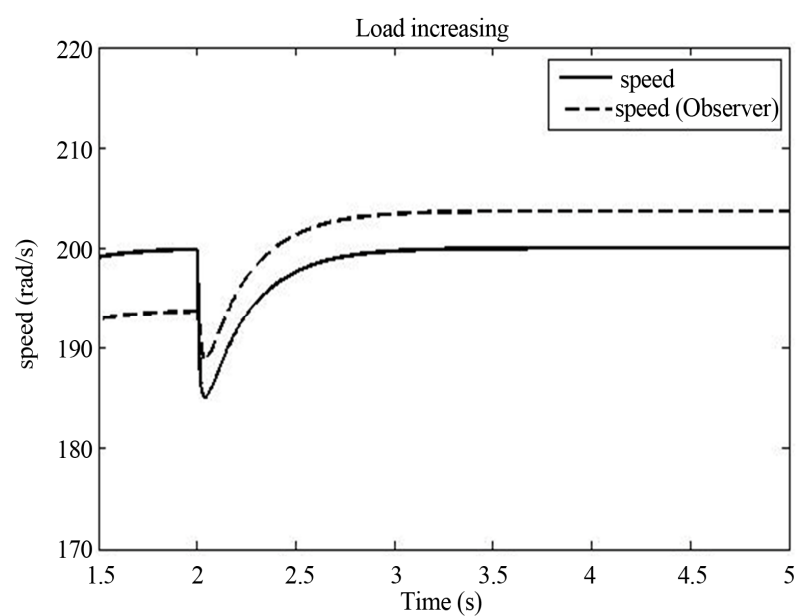

(a)
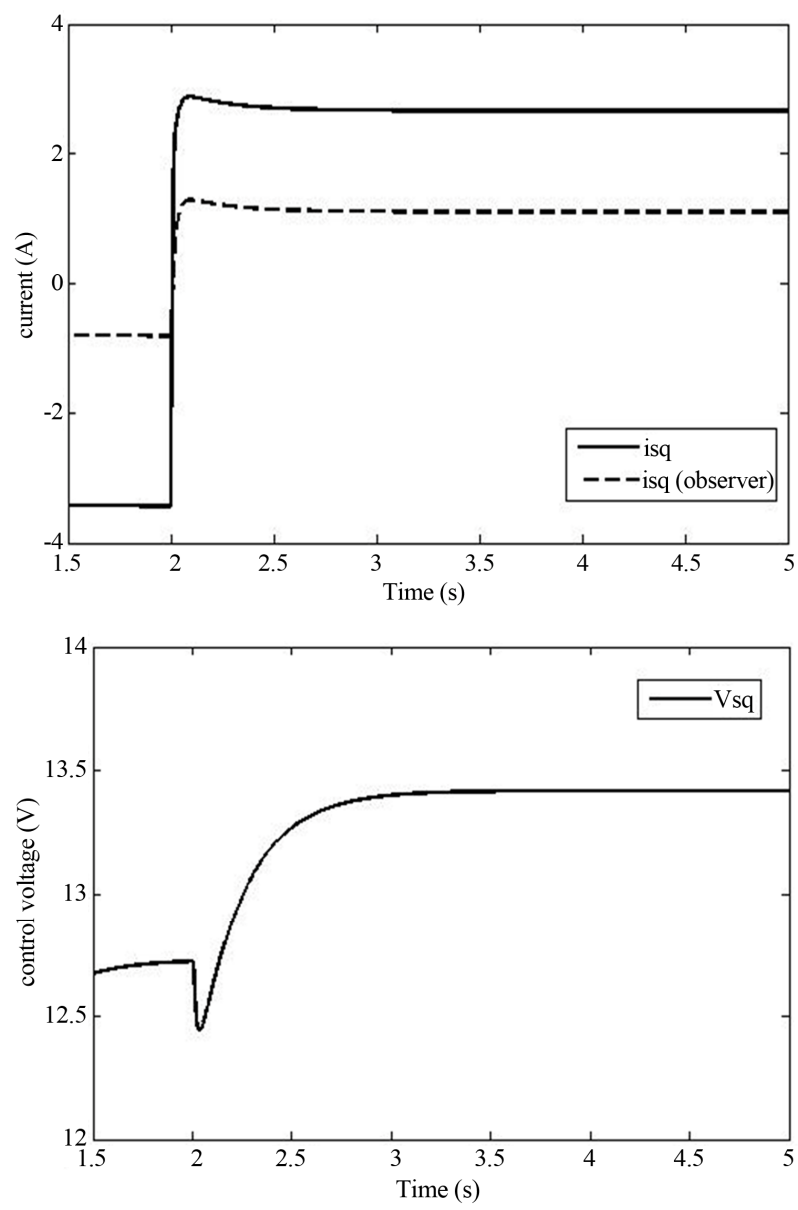

(b)

Figure 7. (a) Speed response; (b) Control signal response for observer acting alone (increase load).

the load disturbance is applied at $\mathrm{t}=2 \mathrm{~s}$. The simulation results are shown in Figures $\mathbf{7}$ and $\mathbf{8}$ for the increasing load. Figures $\mathbf{9}$ and $\mathbf{1 0}$ shows the situation for the decreasing load.

From the obtained result, it is evident that the speed

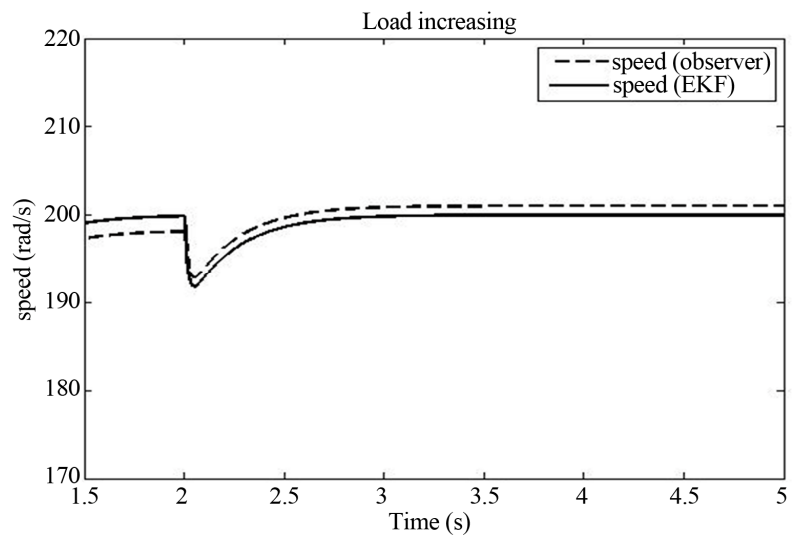

(a)
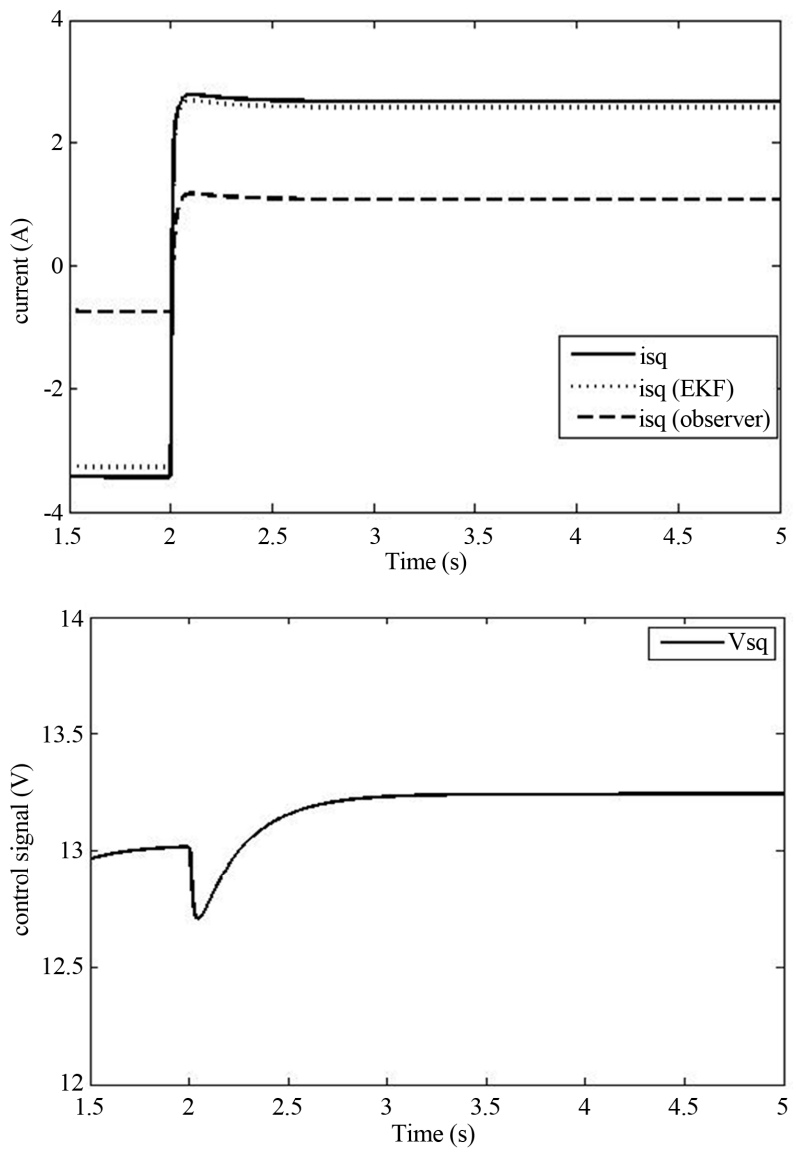

(b)

Figure 8. (a) Speed response; (b) Control signal response for observer combined with EKF (increase load).

variation caused by the load disturbance is significantly reduced in the case where the observer is combined with the EKF as compared with the case where the observer is acting alone. Also, as the simulations show, the input signal variation is reduced. The proposed approach mitigates speed deviation caused by the load disturbance variations. Reduction in the transient input signal variation, reduces the risk of potential input signal saturation, 


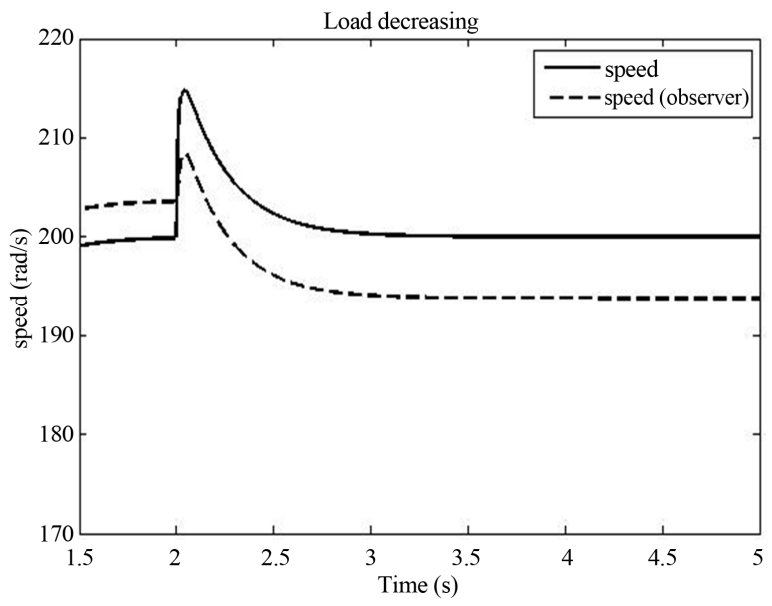

(a)
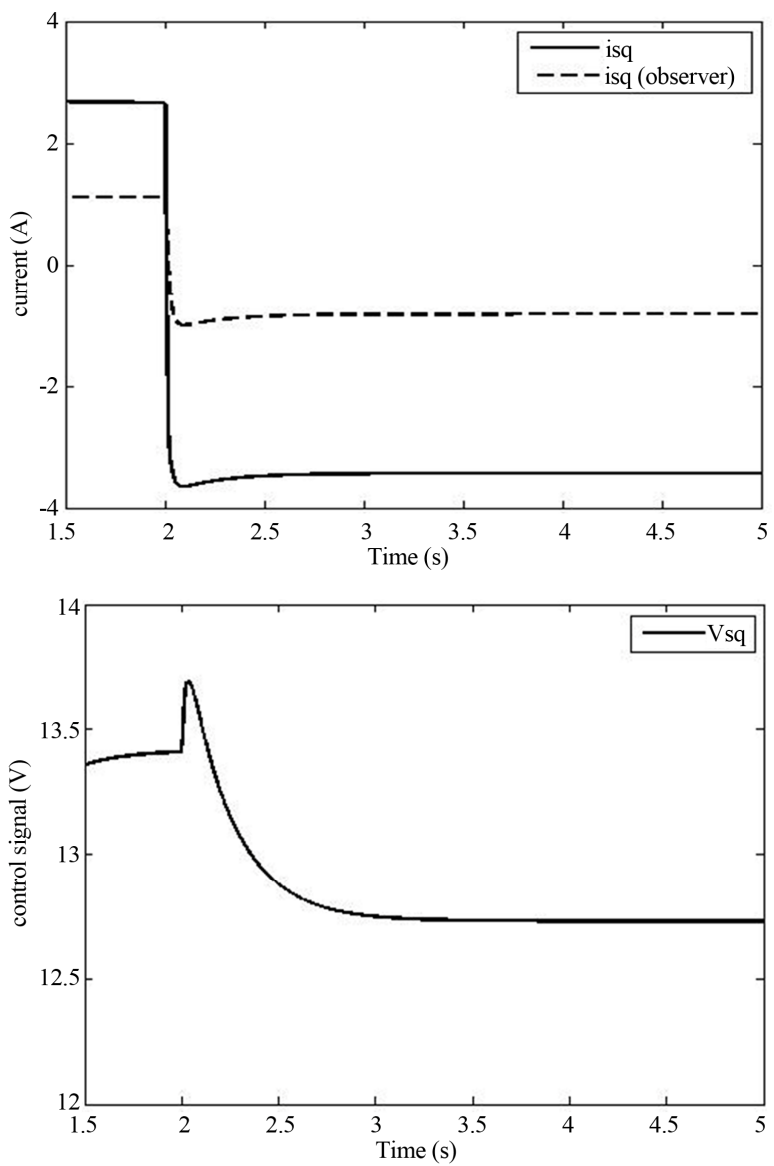

(b)

Figure 9. (a) Speed response; (b) Control signal response for observer acting alone (decrease load).

and prevents the deterioration of the system performance. The simulation results are confirms the effectiveness of the proposed method.

\section{Conclusion}

A novel digital implementation of speed controller for a

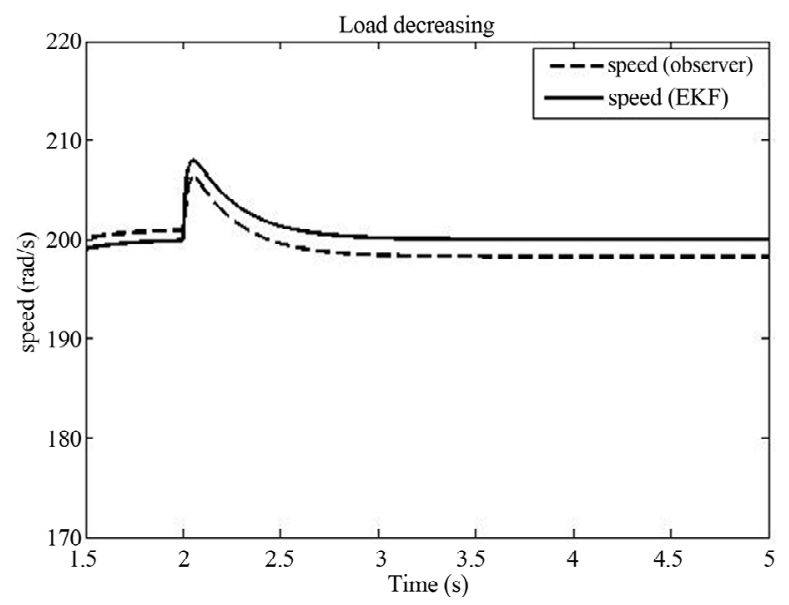

(a)
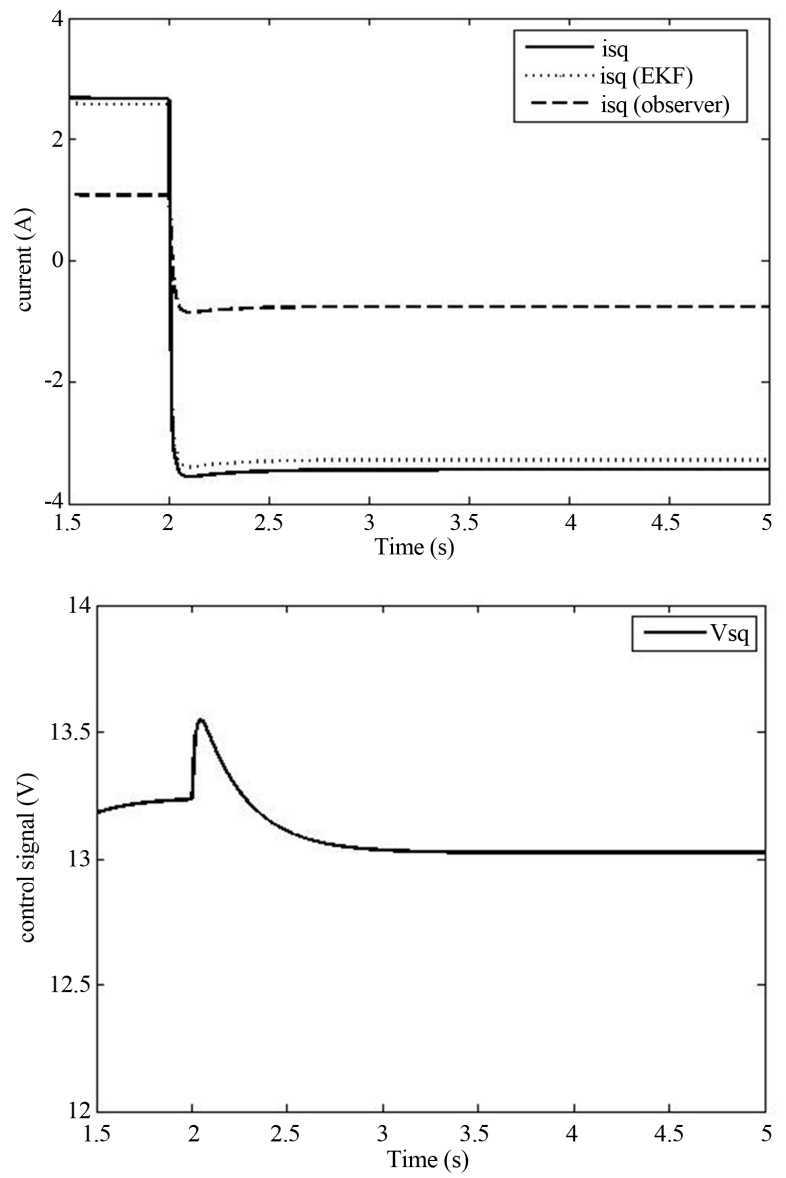

(b)

Figure 10. (a) Speed response; (b) Control signal response for observer combined with EKF(decrease load).

Permanent Magnet Synchronous Motor (PMSM) with disturbance rejection using conventional observer combined with Extended Kalman Filter (EKF) is proposed. The observer combined with EKF algorithm method attenuates the speed deviation caused by the load disturbance. In addition, the magnitude of the variation in the 
control signal is much less compared to the situation with an observer alone. The saturation of input and state is reduced effectively and the system performance is enhanced significantly.

\section{REFERENCES}

[1] S. Srikanth, B. Ranganaik and M. Srinivas Rao, "Spacevector PWM Techniques and High Temperature Super Conducting PMSM Machines with Multilevel Inverter," Proceedings of IEEE-International Conference on Advances in Engineering, Science and Management (ICAESM), Nagapattinam, 30-31 March 2012, pp. 522-527.

[2] Y. Luo, Y. Q. Chen, H.-S. Ahn and Y. Pi, "Dynamic High Order Periodic Adaptive Learning Compensator for Cogging Effect in Permanent Magnet Synchronous Motor Servo System," IET Control Theory \& Applications, Vol. 5, No. 5, 2011, pp. 669-0680. http://dx.doi.org/10.1049/iet-cta.2009.0544

[3] Y. A.-R. I. Mohamed, "Design and Implementation of a Robust Current-Control Scheme for a PMSM Vector Drive with a Simple Adaptive Disturbance Observer," IEEE Transactions on Industrial Electronics, Vol. 54, No. 4, 2007, pp. 1981-1988. http://dx.doi.org/10.1109/TIE.2007.895074

[4] N. Mohan and Electric Drives, "An Integrative Approach,” MNPERE, Minneapolis, 2000.

[5] P. Pillay and R. Krishnan, "Application Characteristics of Permanent Magnet Synchronous and Brushless DC Motors for Servo Drives," IEEE Transactions on Industry Applications, Vol. 27, No.5, 1991, pp. 986-996. http://dx.doi.org/10.1109/28.90357

[6] N. Mohan, "Advanced Electric Drives, Analysis, Control and Modeling Using Simulink," MNPERE, Minneapolis, 2001.

[7] L. S. Shieh, H. M. Dib and S. Ganesan, "Linear Quadratic Regulators with Eigenvalue Placement in a Specified Region," Automatica, Vol. 24, No. 6, 1988, pp. 819-823. http://dx.doi.org/10.1016/0005-1098(88)90058-1

[8] Y. P. Zhang, C. M. Akujuobi, W. H. Ali, C. L. Tolliver and S. Leang-san, "Load Disturbance Resistance Speed Controller Design for PMSM," IEEE Transaction on Industrial Electronics, Vol. 53, No. 4, 2006, pp. 1198-1208. http://dx.doi.org/10.1109/TIE.2006.878313

[9] F. Benchabane, A. Titaouine, O. Bennis, K. Yahia and D. Taibi, "Systematic Fuzzy Sliding Mode Approach with Extended Kalman Filter for Permanent-Magnet Synchronous Motor," Proceedings of the IEEE international conference on Systems Man and Cybernetics (SMC), 2010, pp. 2169-2174.

[10] S. Bolognani, S. Calligaro and R. Petrella, "Sensorless Control of IPM Motors in the Low-Speed Range and at Standstill by HF Injection and DFT Processing," IEEE Transactions on Industry Applications, Vol. 47, 2011, pp. 96-104.

[11] J. lee, J. Hon and K. Nam, "Sensorless Control of Surface-Mount Permanent-Magnet Synchronous Motors Ba- sed on a Nonlinear Observer," IEEE Transactions on Power Electronics, Vol. 25, No. 2, 2010, pp. 290-297. http://dx.doi.org/10.1109/TPEL.2009.2025276

[12] Z. D. Zheng, Y. D. Li, M. Fadel and X. Xiao, “A Rotor Speed and Load Torque Observer for PMSM Based on Extended Kalman Filter," Proceedings of the IEEE international conference on Industrial Technology, Mumbai, 15-17 December 2006, pp. 233-238.

[13] Q. T. An, L. Sun and B. Li, "Variable Parameters EKF for Speed Estimation of PMSM," Electric Machines and Control, Vol. 11, No. 6, 2007, pp. 559-563.

[14] G. C. Zhu, L.-A. Dessaint, O. Akhrif and A. Kaddouri, "Speed Tracking Control of a Permanent-magnet Synchronous Motor with State and Load Torque Observer," IEEE Transaction on Industry Electronics, Vol. 47, No. 2, 2000, pp. 346-355.

[15] T.-J. Kweon and D.-S. Hyun, "High-Performance Speed Control of Electric Machine Using Low-Precision Shaft Encoder," IEEE Transactions on Power Electronics, Vol. 14, No. 5, 1999, pp. 838-849. http://dx.doi.org/10.1109/63.788480

[16] A. Bado and S. Bolognani, "Effective Estimation of Speed and Rotor Position of a PM Synchronous Motor Drive by a Kalman Filtering Technique," 23rd Annual IEEE Power Electronics Specialists Conference, Toledo, 29 June-3 July 1992, pp. 951-957.

[17] K. Shedbalkar, A. P. Dhamangaonkar and A. B. Patil, "Speed Estimation Using Extended Kalman Filter for PMSM," Proceedings of International Conference on Emerging Trends in Electrical Engineering and Energy Management (ICETEEEM), Chennai, 13-15 December 2012, pp. 433-435.

[18] D. Janiszewski, "Extended Kalman Filter Based Speed Sensorless PMSM Control With Load Reconstruction," Procedings of 32nd IEEE Annual Conference on Industrial Electronic, IECON, 6-10 Novermber 2006, pp. 1465-1468.

[19] E. R. Kalman, "A New Approach to Linear Filtering and Prediction Problems," Transactions of the ASME-Journal of Basic Engineering, Vol. 82, No. Series D, 1960, pp. $35-45$.

[20] G. Welch and G. Bishop, “An Introduction to the Kalman Filter, Technical Report 95-041," Department of Computer Science, University of North Carolina at Chapel Hill, Chapel Hill, 1995.

[21] R. Dhaouadi, N. Mohan and L. Norum, "Design and Implementation of an Extended Kalman Filter for the State Estimation of a Permanent Magnet Synchronous Motor," IEEE Transactions on Power Electronics, Vol. 6, 1991, pp. 491-49. http://dx.doi.org/10.1109/63.85891

[22] S. Bolognani, L. Tubiana and M. Zigliotto, "Extended Kalman Filter Tuning in Sensorless PMSM Drives," IEEE Transactions on Industry Applications, Vol. 39, No. 6, 2003, pp. 276-281. 